\title{
Serum autoantibodies and immunoglobulins in hepatitis-associated antigen (HAA)-positive and -negative liver disease
}

\author{
F. J. DUDLEY, M. J. O'SHEA, A. AJDUKIEWICZ, AND S. SHERLOCK
}

From the Departments of Medicine and Haematology, Royal Free Hospital, London

SUMMARY Serum immunoglobulin $\mathrm{G}, \mathrm{A}$, and $\mathrm{M}$ and serum antinuclear, mitochondrial, and smooth muscle antibody have been measured in 223 patients with hepatitis-associated antigen (HAA)positive and -negative acute and chronic liver disease. In patients with acute hepatitis, chronic persistent hepatitis, and primary liver cell carcinoma, these indices failed to show any significant differences. However, in the group with chronic aggressive hepatitis the patients who were HAA negative had significantly higher levels of serum IgG, much higher titres of smooth muscle antibody, and often antinuclear and mitochondrial antibodies which were not found in the HAA-positive patients from this group. This suggests that different pathogenic mechanisms may be operative in HAA-positive and -negative chronic aggressive hepatitis.

Hepatitis-associated antigen has been found in the sera of a variable proportion of patients with different clinical and histological types of acute and chronic liver disease (Blumberg, Gerstley, Hungerford, London, and Sutnick, 1967; Prince, 1968; Wright, McCollum, and Klatskin, 1969; Sherlock, Fox, Niazi, and Scheuer, 1970). The transient presence of HAA is seen in association with either clinical or anicteric acute hepatitis (Krugman and Giles, 1970). Persistence of HAA may be associated with minimal disturbance of liver morphology (Reinicke, Dybkjaer, Poulsen, Banke, Lyllof, and Nordenfelt, 1972), chronic persistent or aggressive hepatitis (Nielsen, Dietrichson, Elling, and Christoffersen, 1971), active cirrhosis (Prince, 1971), and possibly primary liver cell carcinoma (Sherlock, Fox, Niazi, and Scheuer, 1970). The presence of HAA in these patients is thought to implicate the inefective agent responsible for long-incubation, type B hepatitis in the pathogenesis of the associated liver disease (Prince, 1968; Giles, McCollum, Berndtson, and Krugman, 1969) and to separate such patients aetiologically from HAA-negative liver disease of similar pathology. It is possible that different pathogenic mechanisms may be acting to produce a similar histological picture in HAApositive and -negative liver disease, and immunological evaluation of such patients could possibly Received for publication 12 January 1973. detect any such differences. We have measured serum immunoglobulins and autoantibody levels in a large number of HAA-positive and -negative patients with both acute and chronic liver disease to determine if such immunological differences can be detected.

\section{Patients}

Sera from 223 patients with acute and chronic liver disease have been studied. Sera from 50 healthy blood donors served as controls. The patients were divided into different groups including acute hepatitis, chronic aggressive hepatitis, and/or cirrhosis, chronic persistent hepatitis, and primary liver cell carcinoma. Diagnosis was based on both clinical and biochemical findings and was confirmed histologically in all patients with chronic liver disease. Each group was subdivided into those whose serum was HAA positive and those whose serum was HAA negative. The number of patients in each group, their sex distribution, average age, serum bilirubin, and aspartate transaminase levels are seen in the table. Sera from patients with HAAnegative acute hepatitis was obtained during an outbreak of hepatitis which has already been described. All patients affected by the epidemic were consistently HAA negative and the incubation period when documented was usually two to three 


\begin{tabular}{|c|c|c|c|c|c|c|}
\hline Diagnosis & HAA Status & No. & Average Age & Males/Females & $\begin{array}{l}\text { Serum } \\
\text { Bilirubin } \\
(\mathrm{N}<0.8 \mathrm{mg} / 100 \mathrm{ml})\end{array}$ & $\begin{array}{l}\text { Serum Aspartate } \\
\text { Transaminase } \\
(\mathrm{N}<15 \text { iu/l) }\end{array}$ \\
\hline $\begin{array}{l}\text { Chronic } \\
\text { aggressive } \\
\text { hepatitis }\end{array}$ & $\begin{array}{l}+ \\
-\end{array}$ & $\begin{array}{l}34 \\
39\end{array}$ & $\begin{array}{l}43 \cdot 8 \\
24 \cdot 0\end{array}$ & $\begin{array}{c}32 / 2 \\
8 / 31\end{array}$ & $\begin{array}{l}1.8 \\
1.7\end{array}$ & $\begin{array}{l}67 \\
57\end{array}$ \\
\hline $\begin{array}{l}\text { Chronic } \\
\text { persistent } \\
\text { hepatitis }\end{array}$ & $\begin{array}{l}+ \\
-\end{array}$ & $\begin{array}{l}16 \\
11\end{array}$ & $\begin{array}{l}39 \cdot 4 \\
34\end{array}$ & $\begin{array}{r}11 / 5 \\
5 / 6\end{array}$ & $\begin{array}{l}0.9 \\
1.0\end{array}$ & $\begin{array}{l}25 \\
30\end{array}$ \\
\hline $\begin{array}{l}\text { Primary } \\
\text { liver cell } \\
\text { carcinoma }\end{array}$ & $\begin{array}{l}+ \\
-\end{array}$ & $\begin{array}{r}9 \\
14\end{array}$ & $\begin{array}{l}42 \cdot 2 \\
51\end{array}$ & $\begin{array}{r}8 / 1 \\
12 / 2\end{array}$ & $\begin{array}{l}1 \cdot 8 \\
2 \cdot 3\end{array}$ & $\begin{array}{l}56 \\
51\end{array}$ \\
\hline
\end{tabular}

Table Details of the patients

weeks (Ajdukiewicz, Dudley, Fox, Doniach, and Sherlock, 1972). Sera from all the other patients in this study were either obtained when they were first seen at the Royal Free Hospital or during attendance at follow-up clinics. The HAA-positive and -negative subgroups of the patients with primary liver cell carcinoma were well matched for age, sex, and liver function. In all other histological categories a male predominance was seen in the HAA-positive patients whereas females were more common among the HAA-negative patients. Otherwise patients with chronic persistent hepatitis were well matched. Serum bilirubin and aspartate transaminase levels were similar in HAA-positive and -negative chronic aggressive hepatitis but the average age was higher in the HAA-positive group. The HAA-positive and -negative patients with acute hepatitis were poorly matched, those who were HAA positive being much older with more severe liver disease.

\section{Methods}

Serum collected from each patient was stored at $-20^{\circ} \mathrm{C}$ until the day of testing. Each serum specimen was coded and tested without knowledge of the source.

Hepatitis-associated antigen was detected in the sera using a standard human antiserum which gave reactions of identity with antisera from Prince and Blumberg (Fox, Niazi, and Sherlock, 1969). This antiserum was used to detect HAA either by twodimensional gel diffusion, counterimmunoelectrophoresis, or complement fixation.

Serum IgG, IgA, and IgM levels were estimated by the radial immunodiffusion method (Fahey and McKelvey, 1965) using immunoplates and standards prepared by Hyland laboratories and results were expressed as $\mathrm{mg} / 100 \mathrm{ml}$.

Antinuclear, mitochondrial, and smooth muscle antibodies were detected by the indirect immuno- fluorescent technique (Holborow and Johnson, 1964). This was modified by the introduction of fixation for three minutes in absolute ethanol at room temperature before placing the fluorescein-labelled immunoglobulin serum on the tissue sections. All sera were tested at dilutions of $1: 10$ and $1: 40$ on rat kidney and stomach (fundus) sections cut from material which had been frozen in isopentane chilled to its melting point in liquid nitrogen. The results were read with a Reichert Zetopan microscope using quartz iodine illumination. Weak positive reactions were ignored, moderate reactions recorded as positive, and strong reactions at 1:40 were further titrated.

\section{Results}

SERUM IMMUNOGLOBULINS AND AUTOANTIBODIES IN HEALTHY PERSONS

Serum immunoglobulin levels were measured in 50 healthy persons. Serum IgG levels ranged between 580 and $1650 \mathrm{mg} / 100 \mathrm{ml}$. IgA levels were between 75 and $580 \mathrm{mg} / 100 \mathrm{ml}$ and IgM levels between 38 and $215 \mathrm{mg} / 100 \mathrm{ml}$. Serum autoantibodies were sought in 35 controls. Smooth muscle antibody was found in six but only at a titre of 1:10. Antinuclear and mitochondrial antibodies were not found.

SERUM IMMUNOGLOBULINS IN HAA-POSITIVE AND -NEGATIVE PATIENTS (FIG 1)

Some patients from each diagnostic group had raised serum IgG levels but this was most common and marked in the patients with chronic aggressive hepatitis. In each group the incidence of raised IgG levels was roughly similar in the HAA-positive and -negative subgroups. However, of the patients with chronic aggressive hepatitis the IgG levels were significantly higher $(P<0.05)$ in the group which was HAA negative. Serum IgG levels were not significantly different in the HAA-positive and -negative 


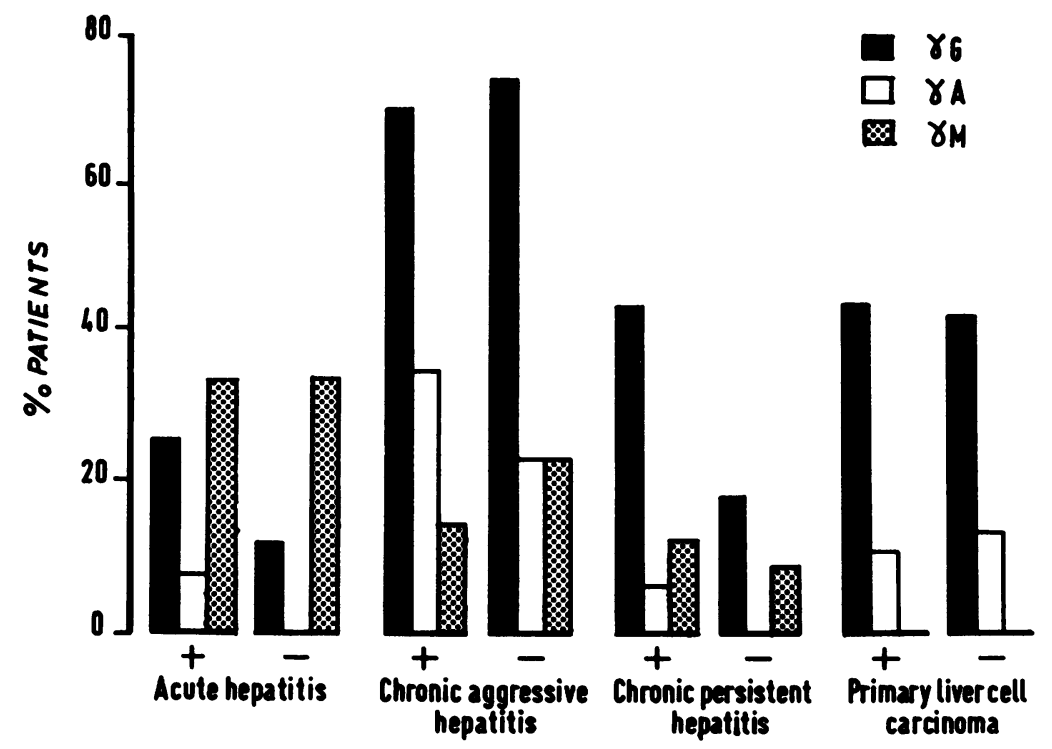

Fig 1 Incidence of raised immunoglobulin levels in HAA-positive (+) and-negative (-) patients with both acute and chronic liver disease (IgG $>1650$; Ig A > 580; IgM > 215 $\mathrm{mg} / 100 \mathrm{ml})$.

subgroups of the other groups of patients.

Raised serum IgA levels were also seen in each diagnostic group and were most common in patients with chronic aggressive hepatitis. There was no statistical difference in IgA levels of the HAApositive and -negative patients in the different diagnostic groups.

Raised serum IgM levels were seen in all groups of patients except those with primary liver cell carcinoma, being most common in the patients with acute hepatitis. Again there was no statistical difference in IgM levels of the HAA-positive and -negative patients in the different diagnostic groups.

\section{SERUM AUTOANTIBODIES IN HAA-POSITIVE} AND -NEGATIVE PATIENTS

Smooth muscle antibody was found at variable titres in all groups of patients (see fig 2). It was most frequently found in patients with acute hepatitis, less often in patients with chronic aggressive hepatitis, and least in the patients with chronic persistent hepatitis and primary liver cell carcinoma. In each group of patients it was detected with approximately equal frequency in both the HAApositive and -negative subgroups. However, in patients with chronic aggressive hepatitis titres were usually greater than 1:40 in HAA-negative patients and less than 1:40 in HAA-positive patients. In the patients with chronic persistent hepatitis and primary liver cell carcinoma the incidence of smooth muscle antibody was only slightly greater than that found in the control population.
Antinuclear antibody was found in the serum of 22 of 39 patients with HAA-negative chronic aggressive hepatitis, usually at a titre of $1: 40$ or greater. It was only detected in two other patients, one with HAA-negative liver cell carcinoma and one with HAA-positive acute hepatitis.

Mitochondrial antibodies were only detected in HAA-negative chronic aggressive hepatitis, being detected in six of these 39 patients.

\section{Discussion}

It is difficult to distinguish on historical and clinical data between short and long incubation hepatitis occurring sporadically in the community. Parenteral and non-parenteral transmission can occur in both (Krugman and Giles, 1970). The discovery of HAA and of its association with long-incubation infective hepatitis has provided a useful marker for detecting this type of hepatitis (Prince, 1968; Giles et al, 1969). However, as it is detectable only transiently in the serum of such patients a negative test does not exclude the diagnosis (Krugman and Giles, 1970). Viral hepatitis of short incubation can, however, be diagnosed confidently only when it occurs in an epidemic in which the incubation period can be calculated and in which all serum specimens have been consistently HAA negative. In this study the patients with HAA-negative acute hepatitis came from such an epidemic (Ajdukiewicz et al, 1972). As a consequence this has meant that the patients with HAA-positive and -negative acute hepatitis 


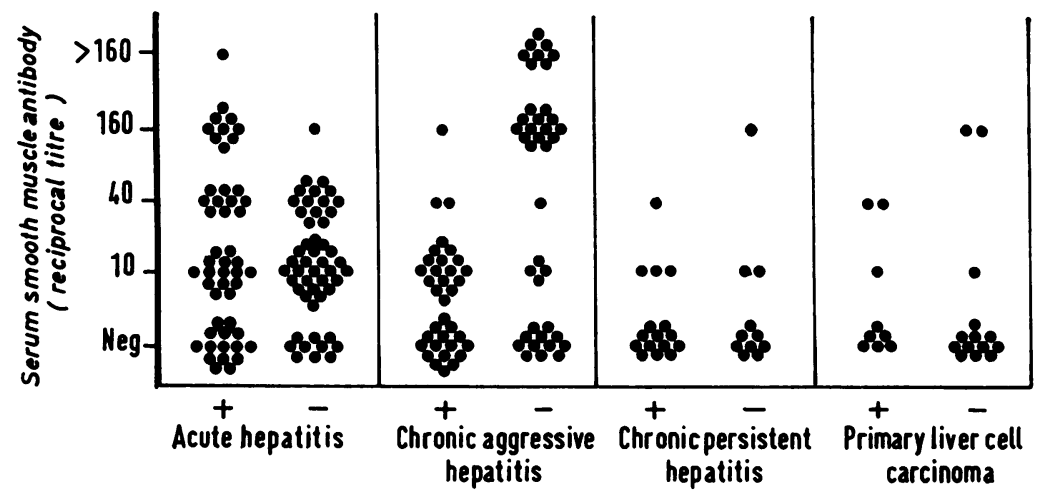

Fig 2 Smooth muscle antibody titres in HAA-positive $(+)$ and -negative (-) patients with both acute and chronic liver disease.

were not matched at all well for age and severity. This fact may well have influenced our results in this group of patients.

Of the patients with acute hepatitis in this study, both the serum immunoglobulin levels and the incidence of smooth muscle antibody were similar in the HAA-positive and -negative subgroups. Other autoantibodies were rarely found. The major abnormality in the serum immunoglobulins was raised IgM levels. There have been a number of other studies on the serum immunoglobulin levels in HAA-positive and -negative hepatitis and the results have been contradictory. Hayashi and LoGrippo (1970) found that serum IgM did not correlate with HAA status in an outbreak of hepatitis in an institution for the mentally retarded. Peters and Ashcavia (1970) also did not find any difference in serum IgG and IgM levels in naturally occurring hepatitis although raised IgG and/or IgM levels were seen in about two-thirds of the patients. In contrast, Giles and Krugman (1969) have found that in mentally retarded children experimentally infected with short-incubation (MS-1) HAA-negative hepatitis there is a high increase in IgM levels occurring shortly after the onset of hepatitis whereas those infected with the long-incubation (MS-2) HAA-positive strain were usually characterized by only slightly elevated or normal IgM levels. This is in agreement with the findings of Peters and Johnson (1972) in a study of serial serum specimens from HAA-positive and -negative patients with acute hepatitis from Panama. Baretto and Klatskin (1972) also found serum IgM levels to be significantly higher in the acute phase of HAA-negative hepatitis than in HAA-positive hepatitis. However, the overlap was great and IgM levels did not clearly distinguish between the two groups. There may be a number of reasons why our study has not confirmed these last three reports. These include the fact that our patients with acute hepatitis were poorly matched, the HAA-positive patients being much older and with more severe disease than the HAA-negative patients. It is also possible that as all our HAA-negative patients came from the same epidemic they were presumably caused by the same strain of hepatitis virus, and this strain may be different from the Willowbrook MS-1 strain or that responsible for HAA-negative hepatitis in Panama. This conclusion could be confirmed by the study of further epidemics of HAA-negative hepatitis.

The presence of smooth muscle antibody was not found to distinguish between HAA-positive and -negative infective hepatitis. This confirms earlier reports (Farrow, Holborow, Johnson, Lamb, Stewart, Taylor, and Zuckerman, 1970; Walker, Doniach, Willette, Cameron, and Dane, 1970). In our study slightly higher titres were occasionally found in the HAA-positive group. This may have been related to the greater severity of the hepatitis in this group as it has been found that titre is related to severity of jaundice in HAA-negative hepatitis (Ajdukiewicz et al, 1972). In contrast to Farrow and his colleagues (1970) we were unable to find any correlation of antinuclear antibody with HAApositive hepatitis.

In the patients with chronic aggressive hepatitis a number of differences were noted between the HAA-positive and -negative groups. In both the major abnormality in serum immunoglobulins was a raised IgG level but this elevation was significantly greater in the HAA-negative patients. A similar incidence of smooth muscle antibody was found in both subgroups but titres were usually much higher in those whose serum was HAA negative. Antinuclear and mitochondrial antibodies were only found in HAA-negative patients. These differences between HAA-positive and -negative chronic aggressive hepatitis are not likely to be related to the severity of the hepatitis as both sub- 
groups had similar mean serum bilirubin and aspartate transaminase levels. The serum immunoglobulin changes and autoantibody levels in the patients with HAA-negative chronic aggressive hepatitis were similar to what has been described previously (Doniach, Roitt, Walker, and Sherlock, 1966; Feizi, 1968). Other studies have rarely found antinuclear and mitochondrial antibody in HAApositive chronic aggressive hepatitis (Vischer, 1970; Bulkley, Heizer, Goldfinger, Isselbacher, and Shulman, 1970). Our results with smooth muscle antibody in HAA-positive chronic aggressive hepatitis correlate less well with other studies. Vischer (1970) found no smooth muscle antibody in any of his patients with HAA-positive chronic liver disease but was only accepting as positive titres of $1: 40$ or greater. Wright (1970) also found no smooth muscle antibody in six patients with HAA-positive chronic aggressive hepatitis and only one of three patients with HAA-positive subacute hepatic necrosis. In that study fluorescein-conjugated antihuman antibody was specific for IgG. Our different results may be partly due to the fact that we have recorded as positive titres greater than or equal to $1: 10$ and that our fluorescein-conjugated antibody was not specific for IgG only.

No immunological differences were detected in this study between patients with HAA-positive and -negative chronic persistent hepatitis or primary liver cell carcinoma. Smooth muscle antibody at titres of 1:10 or more has been found in a high proportion of patients with a variety of malignancies (Whitehouse and Holborow, 1971). However, in our patients with primary liver cell carcinoma smooth muscle antibody was found but did not occur with much greater frequency than in the control population.

In conclusion, measuring serum immunoglobulin levels and autoantibody titres did not detect any significant differences between HAA-positive and -negative patients with acute hepatitis, chronic persistent hepatitis, or primary liver cell carcinoma. However, in patients with chronic aggressive hepatitis those who were HAA negative had significantly higher levels of IgG, much higher titres of smooth muscle antibody, and often antinuclear and mitochondrial antibodies which were not detected in the HAA-positive patients from this group. This suggests that different pathogenic mechanisms may be operative in HAA-positive and -negative chronic aggressive hepatitis.

F.J.D. was supported by a grant from the Wellcome Foundation. Requests for reprints should be addressed to S.S.
References

Ajdukiewicz, A. B., Dudiey, F. J., Fox, R. A., Doniach, D., and Sherlock, S. (1972). Immunological studies in an epidemic of infective, short incubation hepatitis. Lancet, 1, 803-806.

Barreto, V. S. T., and Klatskin, G. (1972). Infectious and serum viral hepatitis. Differentiation with serum IgM and thymol turbidity as criteria. J. Amer. med. Ass., 221, 571-575.

Blumberg, B. S., Gerstley, B. J. S., Hungerford, D. A., London, W. T., and Sutnick, A. I. (1967). A serum antigen (Australia antigen) in Down's syndrome, leukemia, and hepatitis. Ann. intern. Med., 66, 924-931.

Bulkley, B. H., Heizer, W. D., Goldfinger, S. E., Isselbacher, K. J., and Shulman, N. R. (1970). Distinctions in chronic active hepatitis based on circulating hepatitis associated antigen. Lancet, 2, 1323-1326.

Doniach, D., Roitt, I. M., Walker, J. G., and Sherlock, S. (1966). Tissue antibodies in primary biliary cirrhosis, active chronic (lupoid) hepatitis, cryptogenic cirrhosis and other liver diseases and their clinical implications. Clin. exp. Immunol., 1, 237-262.

Fahey, J. L., and McKelvey, E. M. (1965). Quantitative determination of serum immunoglobulins in antibody agar plates. J. Immunol., 94, 84-90.

Farrow, L. J., Holborow, E. J., Johnson, G. D., Lamb, S. G., Stewart, J. S., Taylor, P. E., and Zuckerman, A. J. (1970). Autoantibodies and the hepatitis associated antigen in acute infective hepatitis. Brit. med. J., 2, 693-695.

Feizi, T. (1968). Immunoglobulins in chronic liver disease. Gut, 9, 193-198.

Fox, R. A., Niazi, S. P., and Sherlock, S. (1969). Hepatitis associated antigen in chronic liver disease. Lancet, 2, 609-612.

Giles, J. P., and Krugman, S. (1969). Viral hepatitis. Immunoglobulin response during the course of the disease. J. Amer. med. Ass., 208, 497-503.

Giles, J. P., McCollum, R. W., Berndtson, L. W., and Krugman, S. (1969). Viral hepatitis: relation of Australia/SH antigen to the Willowbrook MS-2 strain. New Engl. J. Med., 281, 119-122.

Hayashi, H., and LoGrippo, G. A. (1970). 'Australia antigenaemia' in institutionalized children 7 years after infectious hepatitis. (Abstr.) Fed. Proc., 29, Abstr. no. 221.

Holborow, J., and Johnson, G. D. (1964). Antinuclear factor in systemic lupus erythematosus: a consideration of the immunofluorescent method of detecting antinuclear antibodies, with results obtained in a family study. Arthr. and Rheum., 7, 119-127.

Krugman, S., and Giles, J. P. (1970). Viral hepatitis: new light on an old disease. J. Amer. med. Ass., 212, 1019-1029.

Nielsen, J. O., Dietrichson, O., Elling, P., and Christoffersen, P. (1971). Incidence and meaning of persistence of Australia antigen in patients with acute viral hepatitis: development of chronic hepatitis. New Engl. J. Med., 285, $1157-1160$.

Peters, R. L., and Ashcavai, M. (1970). Immunoglobulin levels in the detection of viral hepatitis. Amer. J. clin. Path., 54, 102-109.

Peters, C. J., and Johnson, K. M. (1972). Serum immunoglobulin levels in Australia antigen positive and Australia antigen negative hepatitis. Clin. exp. Immunol., 11, 381-391.

Prince, A. M. (1968). An antigen detected in the blood during the incubation period of serum hepatitis. Proc. nat. Acad. Sci. (Wash.), 60, 814-821.

Prince, A. M. (1971). Role of serum hepatitis virus in chronic liver disease. Gastroenterology, 60, 913-921.

Reinicke, V., Dybkjaer, E., Poulsen, H., Banke, O., Lylloff, K., and Nordenfelt, E. (1972). A study of Australia-antigen-positive blood donors and their recipients, with special reference to liver histology. New Engl. J. Med., 286, 867-870.

Sherlock, S., Fox, R. A., Niazi, S. P., and Scheuer, P. J. (1970). Chronic liver disease and primary liver-cell cancer with hepatitis associated (Australia) antigen in serum. Lancet, 1, 1243-1247.

Vischer, T. L. (1970). Australia antigen and autoantibodies in chronic hepatitis. Brit. med. J., 2, 695-698.

Walker, J. G., Doniach, D., Willette, M., Cameron, C. H., and Dane, D. S. (1970). Virus antigen, immunoglobulins and autoantibodies in acute hepatitis. Gut, 11, 369.

Whitehouse, J. M. A., and Holborow, E. J. (1971). Smooth muscle antibody in malignant disease. Brit. med. J., 4, 511-513.

Wright, R. (1970). Australia antigen and smooth muscle antibody in acute and chronic hepatitis. Lancet, 1, 521-522.

Wright, R., McCollum, R. W., and Klatskin, G. (1969). Australia antigen in acute and chronic liver disease. Lancet, 2, 117-121. 